\title{
Scanning Electron Microscopy Analysis of ltrastructural Modifications in Lumbar Intervertebral Discs
}

\author{
Manunta A, Uboldi FM*, Mosele GR and Doria C \\ Orthopedic Unit, Italy \\ *Corresponding author: Uboldi FM, Orthopedic Unit, Italy
}

Submission: 眥 October 27, 2018; Published: 制 November 14, 2018

\begin{abstract}
Objective: Morphological and descriptive analysis on different features of ultrastructural lumbar intervertebral discs during physiological and pathological conditions.

Design: This study was conducted on 33 anatomical preparations of L4-L5 and L5-S1 from cadavers, classified between normal and pathological according to Rolander criteria, and subsequently analysed by using scanning electron microscopy (SEM) technique.

Results: 7 out of 33 discs were classified as normal and 26 as pathological; SEM analysis showed a lamellar structure made of collagen fibres arranged as concentric bundles connected by annulus fibrosus cross-bridges, while the nucleus pulposus appeared as if consisting of a fibril substance arranged on an irregular pattern to form a sort of weave formed by softer fibres. Conversely, degenerative processes in pathological discs may be identified as fissures, especially through a radial arrangement from the third internal to the middle one in the annulus. Discs classified as normal showed microfissures especially on the external wall of the annulus.
\end{abstract}

Conclusion: Based on our observations, external microfissures can be considered a result of disc physiological involution and are not related to any degenerative process affecting the disc, which are instead represented by circumferential and radial fissures located on the posterior region.

Keywords: Degenerative intervertebral disks; Electron probe microanalysis; Fibrillar collagen; Annulus fibrosus

\section{Introduction}

The first description of normal intervertebral discs and potential degenerative or involutive processes was introduced by Schmorl e Junghanns [1]: by using optical microscope they reported the occurrence of visible microscopical fissures extending from the nucleus pulposus towards the annulus and associated to the disc hydration status. Several accurate studies have been subsequently conducted on disc physiological anatomy and on its secondary modifications due to a pathological process and caused by ageing. Since the beginning, the most relevant investigations on this issue Methods reported fissures having the shape of radial concentric cracks that may be extended to the whole annulus thickness, undoubtedly associated to the mechanical stress suffered [2-4]. The subject of the current investigation was the morphological and descriptive analysis on different features by using ultrastructural and scanning electron microscopy (SEM) techniques of lumbar intervertebral discs classified as normal as well as on modifications that might occur because of involutive and degenerative processes.

Table 1: Rolander [5] Classification. This classification provides a measure of "disc quality".

\begin{tabular}{|c|c|}
\hline 0 & Macroscopically normal discs, both nucleus and annulus are white and clearly distinct from each other \\
\hline 1 & Discs with normal appearance, although the nucleus is more fibrous. There is still a distinct boundary between nucleus and annulus. \\
\hline 2 & $\begin{array}{c}\text { Less distinct boundary between nucleus and annulus, colour change from white to yellowish brown. There may be an isolated fissure in the } \\
\text { annulus. }\end{array}$ \\
\hline 3 & Clear disc degeneration with desiccation, multiple fissures in nucleus and annulus and disc thinning. \\
\hline
\end{tabular}

The present study was conducted according to the Helsinki Declaration (World medical Association) on patients who had given their consent to the post-mortem donation of muscle-tissue and bone samples. Observations were conducted on 33 intervertebral lumbar discs (24 male and 9 female subjects, average age 61, range 29-78); intervertebral spaces collected were L4-L5 in 29 cases and 
L5-S1 in 14 cases. Discs were classified as normal or pathological based on macroscopical appearance of collected discs, based on height, diameter, thickness and colour following Rolander [5] criteria Table 1. Based on these criteria, disc status, medical history and X-rays if available, a total of 4 L4-L5 discs were classified as normal and 15 pathological; for what concerns L5-S1 discs, a total of 3 resulted normal and 11 were pathological. The sample collection method was designed in order to allow the whole disc to be extracted. Moreover, samples were prepared following standard procedure for SEM investigation (Isi model DS- 130).

\section{Results}

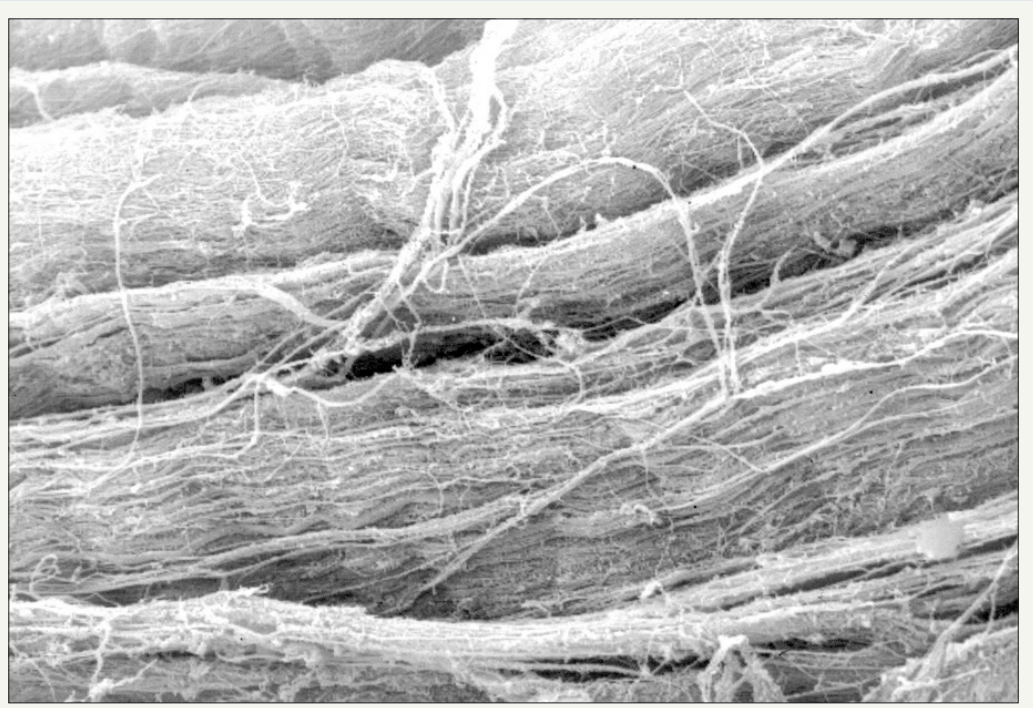

Figure 1: Densely packed collagenous fibers with apparently unidirectional course.

The study of preparations obtained from annulus fibrosus showed at highest resolution a lamellar structure arranged on concentric layers; lamellae consists of fibre bundles being orthogonally or perpendicularly oriented to the contiguous lamellae Figure 1.

A lamellar pattern similar to geological layers was observed on the sliced area of preparations under analysis; furthermore, at higher resolution the lamellae layer seemed formed by collagen fibres very closely connected having a $15-20 \mu \mathrm{m}$ thickness and being uniformly oriented following a bundle arrangement. Figure 2 . Sporadic polygonal and flat cells were found on sections tangential to lamellae showing some lacunae inside the cell matrix Figure 3.
Even in discs classified as normal, bundles under analysis showed a sinuous pattern with microfissures more frequently found. On the other hand, in annulus samples taken from discs classified as pathological, fissures involved mostly the connecting area located between the third median and the third central and tended to have a radial arrangement Figure 4. At higher resolution lamellae can be observed in an area where they appear unstuck from each other; however, they still look connected to each other by cross-bridges indicating their strong adhesion in the past Figure 5 [6]. During degenerative process advancement, the arrangement of annulus fibres showed a sinuous aspect or a spiral shape as a result of sagging or relaxation probably due to the ageing process Figure 6.

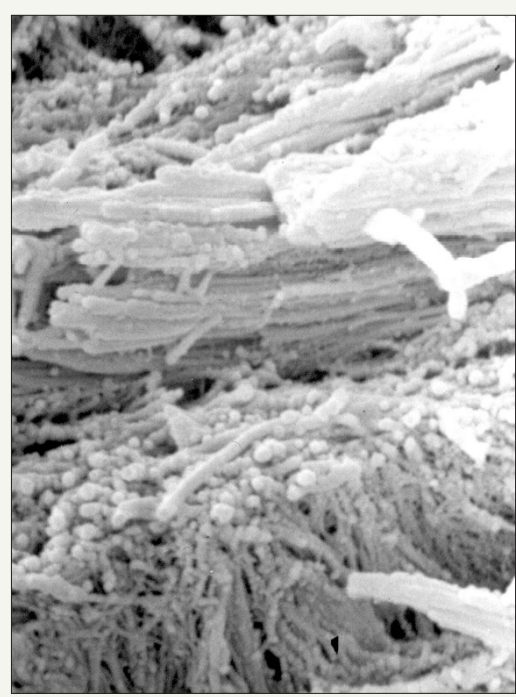

Figure 2: The normal disk architecture had a three-dimensional complex structure with parallel arrangement. 


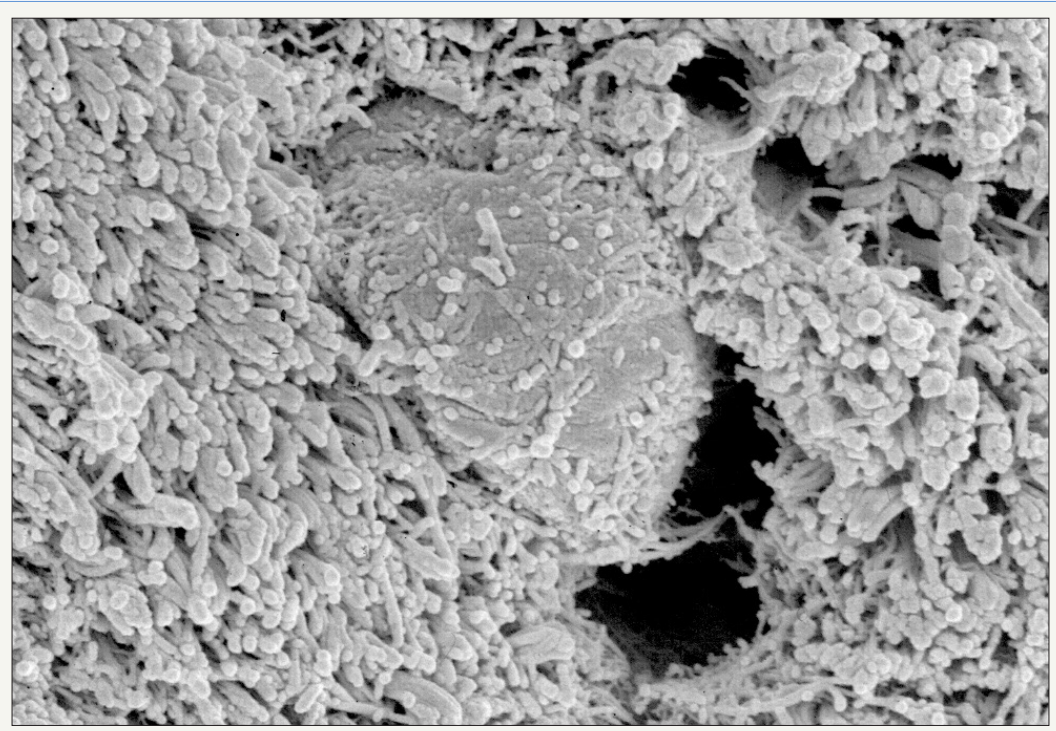

Figure 3: Between interfibrillar collagen architecture, rounded and flattened cell are detectable.

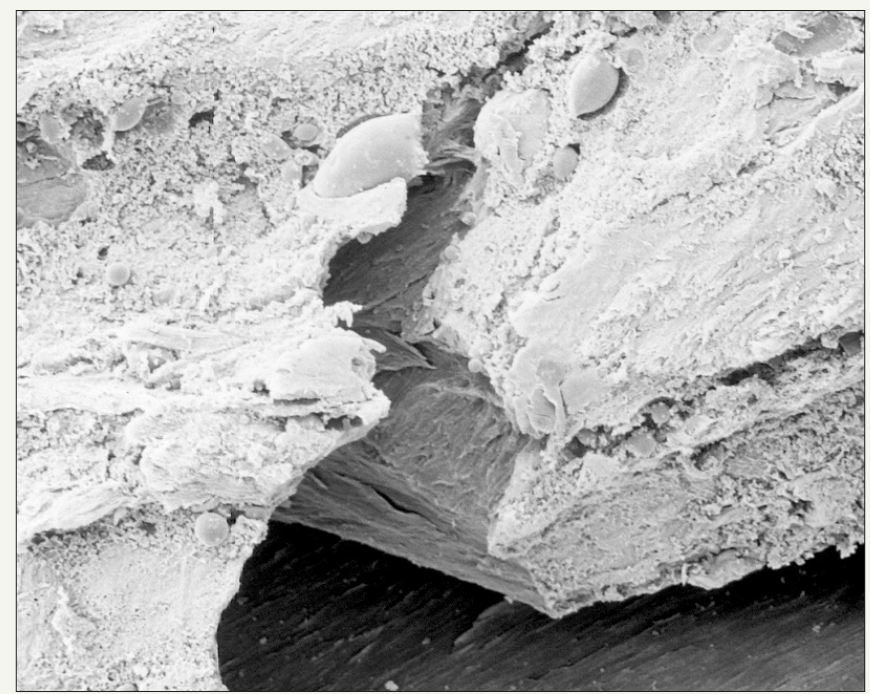

Figure 4: Radial fissure in a patient of "normal disks" group with damage of fibers' architecture.

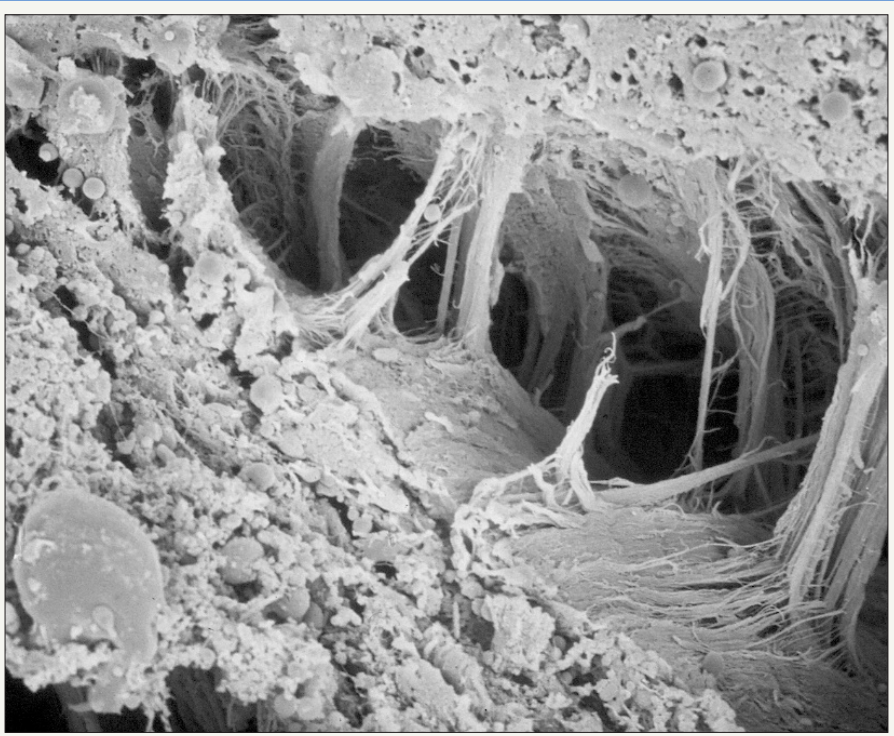

Figure 5: Dramatic changes of interfibrillar collagen network directly near the rupture zone. 


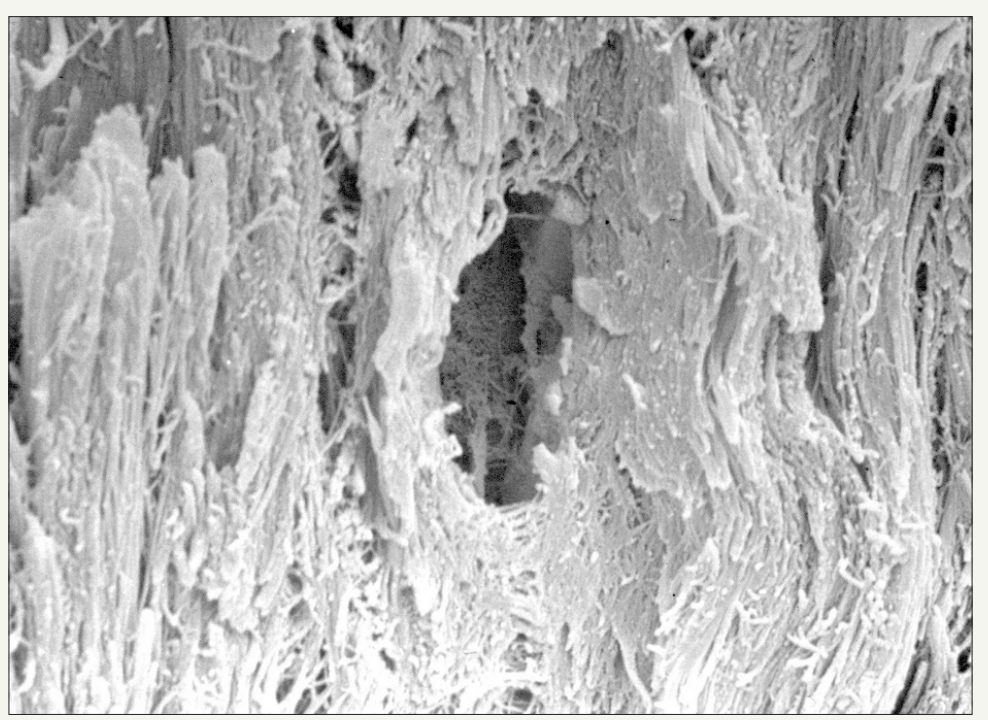

Figure 6: Loss of collagen density and more wavy course of the fascicles.

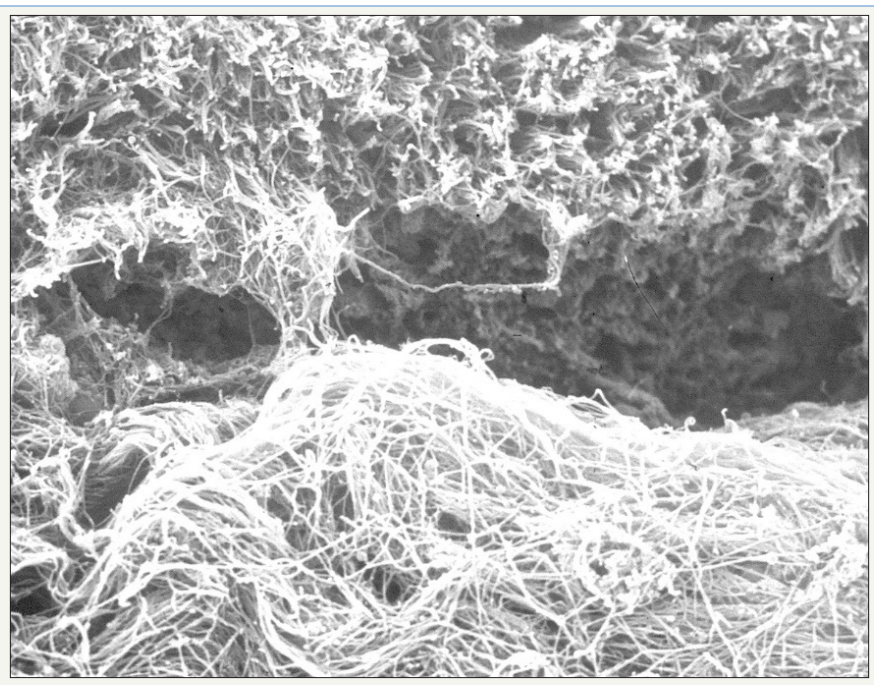

Figure 7: The nucleus pulposus core under the pressure of the vertebral disc has a high content in proteoglycans and it has a connective structure whitout chondrocytes.

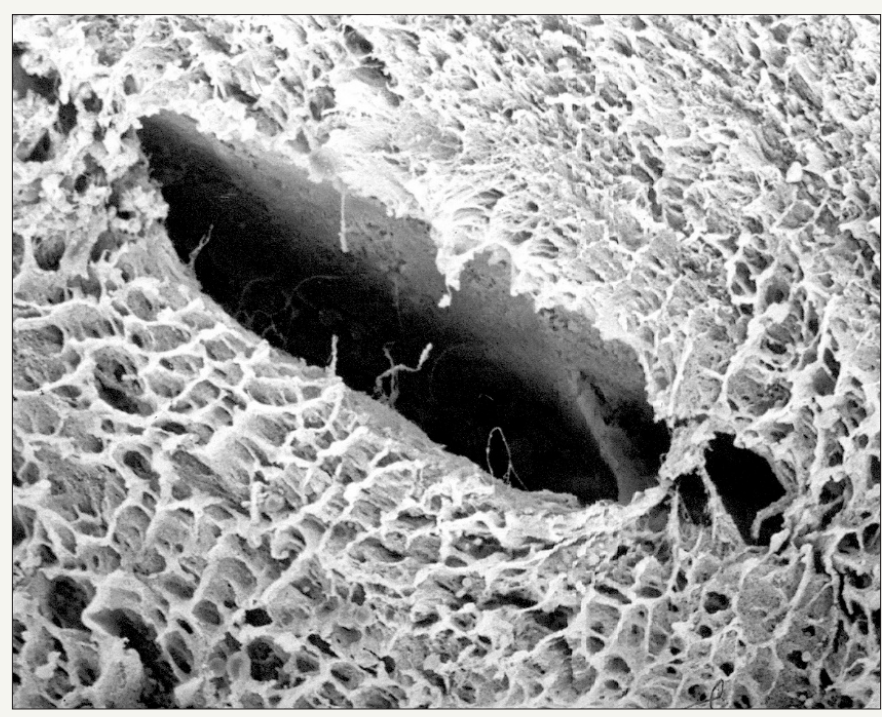

Figure 8: The porous structure of nucleus allows easily penetration of inflammatory cells and vascular coins that facilitate the comunication with lamellar disk arrangement. 
The nucleus pulposus collected from discs classified as normal, appeared as a fibrillar substance arranged on an irregular pattern compared to the more organized annulus architecture that forms a sort of softer fibre weave. Inside the most internal area of discs classified as pathological, fibrils are organized to form a structure based on overlapping rows Figure $7 \& 8$. At higher resolution a fibrillar cribrous surface can be observed, indicating an identical presentation of collagen fibres. In some disc samples from patients over 70 years of age, it was possible to find spread microscopical areas arranged on a nodular pattern and formed by amorphous substances probably of amyloid nature [7].

\section{Discussion}

The present morphological study based on SEM enable us to get a really suggestive $3 \mathrm{D}$ view on some aspects of the nucleus and annulus fibrosus intervertebral disc ultrastructural organization. Although these entities are already known [8], our study highlighted some anatomopathological aspects related to involutive and degenerative processes at the time of their first manifestation. These processes are indeed also very visible in discs classified as normal and may play an important role on involtution of pathological processes.

The fact that microfissures were found on the external part of the annulus even in discs classified as normal leads us to the hypothesis that these cracks may be the result of disc physiological involution and are not related to degenerative processes. Instead in pathological discs the most important finding are annulus fissures that resemble a rim lesion first phase reported by Anglo-saxon researchers [9]. At first sight the latter might be connected to an increase of intradiscal pressure and to secondary annulus fibres tear; in fact, during degenerative process this happens after the appearance of circumferential lesions and then of radial lesions on the annulus posterior region [10]. The latter is mostly encountered in older individuals and it is associated to a degenerated nucleus pulposus. According to our observations, these lesions characterize degenerative processes parallel to involutive processes and may play an important key-role in herniated disc pathogenesis as well as in chronic degenerative discopathies [11]. The disk hernia sometimes was reported contains fragments of hyaline cartilage, but its origin and its meaning are unclear. In the Lama et al. [12] study it has been shown that it often comes from the cartilage removed during the procedure from the vertebral plates.

\section{Acknowledgement}

Thanks to Lisai P, Rinonapoli G and Marceddu S for their support to this work.

\section{References}

1. Hansson TH, Keller TS, Spengler DM (1987) Mechanical behavior of the humal lumbar spine. II. Fatigue strenght during dynamic compressive loading. J Orthop Res 5(4): 479-487.

2. Coventry MB (1969) Anatomy of the intervertebral disk. Clin Orthop Relat Res 67: 9-15.

3. Friberg S, Hirsch C (1949) Anatomical and clinical studies on lumbar disc degeneration. Acta Orthop Scand 19(2): 222-242.

4. Hirsch C, Schajowicz F (1952) Studies on structural changes in the lumbar annulus fibrosus. Acta Orthop Scand 22(1-4): 184-231.

5. Rolander SD (1996) Motion of the lumbar spine with special reference to the stabilising effect of posterior fusion. Acta Orthop Scand 90: 1-144.

6. Schollum M, Robertson P, Broom N (2009) A microstructural investigation of intervertebral disc lamellar connectivity: detailed analysis of the translamellar bridges. J Anat 214: 805-816.

7. Ladefoged C (1985) Amyloid in intervetebral discs. A histopayhological investigation of intervertebral discs from 30 randomly selected autopsies. Appl Pathol 3(1-2): 96-104.

8. Ambard D, Cherblanc F (2009) Mechanical behavior of annulus fibrosus: a microstructural model of fibers reorientation. Ann Biomed Eng 37(11): 2256-2265

9. Osti OL, Roberts VS, Fraser RC (1990) 1990 Volvo Award in experimental studies. Anulus tears and intervertebral disc degeneration. An experimental study using an animal model. Spine 15(8): 762-767.

10. Iatridis J, Gwynn I (2004) Mechanisms for mechanical damage in the intervertebral disc annulus fibrosus. J Biomech 37(8): 1165-1175.

11. Wade K, Robertson P, Thambyah A, Broom N (2014) How healty discs herniate: A biomechanical and microstructural study investigating the combined effects of compression rate and flexion. Spine 39(13): 10181028.

12. Lama P, Zehra U, Balkovec C, Claireaux HA, Flower L, et al. (2014) Significance of cartilage endplate within herniated disc tissue. Eur Spine J 23(9): 1869-1877.
Creative Commons Attribution 4.0 International License

For possible submissions Click Here

\section{Submit Article}

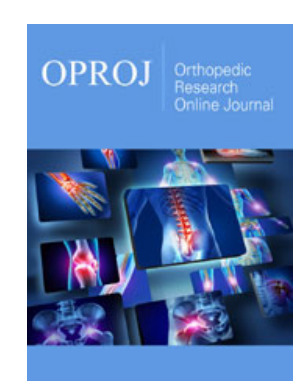

\section{Orthopedic Research Online Journal}

\section{Benefits of Publishing with us}

- High-level peer review and editorial services

- Freely accessible online immediately upon publication

- Authors retain the copyright to their work

- Licensing it under a Creative Commons license

- Visibility through different online platforms 